which overlap, and which, as shown in the cut, are tied together at a point about 4 centimetres above each of the balls. No ball can be laterally displaced without tending to drag its neighbour also ; so that a shearing stress is transmitted along the line of balls. As Reynolds showed twenty years agio, the velocity of propagation of the wave-front differs from that of the group of waves owing to the continual dying away of the amplitude of the advancing waves. This effect, due to the inertia of the medium, is of course equivalent to the presence of dispersion in the medium, waves of different frequencies being propagated with slightly different velocities. So far, therefore, as Prof. Fitzgerald remarked when the model was exhibited, it illustrates the propagation of the wave in a refracting medium rather than in the ether of space. The waves in the model travel quite slowly; and there is a fascination in watching their progress along the row of balls, until they arrive at the resonator and set it into responsive vibration. There is, of course, no attempt made here to represent the magnetic part of the electromagnetic wave, at right angles to the electrostatic part; the mechanical displacements in the model corresponding to the electrostatic displacements of the Hertzian wave. A row of inter-connected pendulums such as this affords a means of illustrating many point in physics. For many purposes the elaborate system of suspension by strings may be replaced by a continuous fabric. Thus, for example, a piece of netting, hung on hooks from a horizontal rail, and ending below in a short fringe, with leaden beads on the fringe-tips, will also serve to illustrate the propagation of a transverse wave. The structure adopted absolutely refuses to transmit longitudinal disturbances; there being no compressional elasticity between the balls to propagate a longitudinal wave. Silvanus P. Tiromison.

\section{Blackbird's Nest appropriated by a White Wagtail.}

I SEE in NATURE of July I 5 (p. 248), a letter to the effect that a wagtail had appropriated a blackbird's nest. I beg to state that on June 12 I had the good fortune to find a similar nest at Coburg in Germany. There was a blackbird's nest behind a summer-house in the garden where I was staying, against the wall about I 6 feet from the ground. The white wagtail had lined it with moss, hair, and thread, and laid six eggs in it, which, together with the nest, are now in my collection. The gardener and myself both identified the bird.

G. W. DE P. NiChoIson.

Jesus College, Cambridge, July 27.

\section{THE ROYAL SOCIETY AND ITS HAND-BOOKS. ${ }^{\mathrm{A}}$}

I $\mathrm{T}$ is with most corporations, and especially with an ancient corporation like the Royal Society, a matte of some practical moment to maintain continuity of life and action, and it is always interesting to record that continuity. The "Record of the Royal Society" has this, apparently, as its aim. The "Year-book of the Royal Society," published some few months ago, contains, so the preface to the "Record" informs us, information which is liable to change, and the "Yearbook" will accordingly be issued annually; but "the 'Record' contains information, largely historical, such as will not need more than slight additions from time to time," and it is intended therefore to issue new editions of this only at intervals of a few years, as may be found desirable.

Reference to the "Year-book," a copy of which has been sent to us with the "Record," shows that it contains such matters as a table of the meetings for the Session, a list of the Fellows, lists of the Council and Committees, the Statutes, standing orders, and regulations for various occasions, the Society's balance-sheet, schedule of estates and property, and much other matter which is strictly and exclusively of official utility and interest. But the "Record," although it has been officially prepared, as we learn from the preface, by the secretaries, aided by Mr. H. Rix, the late assistant secretary, and is in the main

I " The Record of the Royal Society of London," x897, No. x. "Yearbook of the Royal Society of London," $1896-97$, No. I. a hand-book of an official sort intended for official purposes, contains, nevertheless, so much that is historicalso much, let us add, that is quaint and antique in flavourthat it has very considerable general interest.

The volume opens with an "Account of the Foundation and Early History of the Royal Society," in which Sprat's, Thompson's and Weld's histories have been used to some extent, but in which much use has also clearly been made of the original MSS. upon which those histories are based. The story has often been told how, about the year 1645, "divers worthy persons, inquisitive into natural philosophy and other parts of human learning," used to meet in London, sometimes at Dr. Goddard's lodgings in Wood Street, sometimes at the "Bull Head" in Cheapside, and, in term-time, at Gresham College ; how, about I648 or 1649 , some of this company removed to Oxford, where they founded the Philosophical Society of Oxford, while the Londoners continued their meetirigs, usually at Gresham College, until the famous gathering of November 28, 1660, when, after Mr. Wren's lecture, the company being withdrawn for "mutuall converse," "amongst other matters that were discoursed of, something was offered about a designe of founding a Colledge for the promoting of Physico-Mathematicall Experimentall Learning." In the present "Account of the Foundation" the steps are traced by which this meeting led to the foundation of the Royal Society, the Charter of Incorporation passing the Great Seal on July 15,1662 , for which grace on the 29th of that month the President, Council, and Fellows went to Whitehall and returned their thanks to his Majesty.

The compilers of this "Account" lay stress upon the fact that in the infancy of the Society one most important feature of a meeting was the performing of experiments before the members. "The experiment was performed for and by itself, and not merely, as now, in illustration of a 'paper communicated.' Papers were read then as now ; but the reading of such papers formed only a part, and by no means a great part, of the business of the meeting." An example of one of these early meetings is given, and as it does not appear in Weld's "History," and is a very interesting glimpse of seventeenth century science, it may be worth printing it here in full.

\section{September 10th, I662.}

"Mersennus, his account of the tenacity of cylindricall bodies was read by Mr. Croone, to whome the prosecution of that matter by consulting Galilceo, was referred when the translation of that Italian treatise wherein he handleth of this subject shall bee printed.

"It was order'd, that, at the next meeting Experiments should bee made with wires of severall matters of ye same size, silver, copper, iron, \&c., to see what weight will breake them; the curator is $\mathrm{Mr}$. Croone.

"The reading of the french manuscript brought in by Sr. Robert Moray about taking heights and distances by catoptricks was differred till the description of the instrument should come.

"Dr. Goddard made an experiment concerning the force that presseth the aire into lesse dimensions ; and it was found, that twelve ounces did contract $\frac{1}{24}$ part of Aire. The quantity of Air is wanting.

"My Lord Brouncker was desired to send his Glass to Dr. Goddard, to make further experiments about the force of pressing aire into less climensions.

"Dr. Wren was put in mind to prosecute Mr. Rook's observations concerning the motions of the satellites of Jupiter.

"Dr. Charleton read an Essay of his, concerning the velocity of sounds, direct and reflexe, and was desired to prosecute this matter; and to bring his discourse again next day to bee enter'd.

"Dr. Goddard made the Experiment to show how much aire a man's lungs may hold, by sucking up water

$$
\text { NO. } 1450 \text { VOL. } 56]
$$


into a separating glasse after the lungs have been well emptied of Aire. Severall persons of the Society trying it, some sucked up in one suction about three pintes of water, one six, another eight pintes and three quarters $\&$ c. Here was observed the variety of whistles or tones, which ye water made at the severall hights, in falling out of the glasse again.

"Mr. Evelyn's experiment was brought in of Animal engrafting, and in particular of making a Cock spur grow on a Cock's head.

"It was discoursed whether there bee any such thing as sexes in trees and other plants; some instances were brought of Palme trees, plum trees, hollies, Ash trees, Quinces, pionies, \&c., wherein a difference was said to be found, either in their bearing of fruit or in their hardnesse and softness, or in their medicall operations : some said that the difference which is in trees as to fertility or sterility may be made by ingrafting.

"Mention was made by Sr. Rob. Moray of a French Gentleman who having been some while since in England, and present at a meeting of the Society, discoursed that the nature of all trees was to run altogether to wood, which was changed by a certaine way of cutting them, whereby they were made against their nature to beare fruit, and that according as this cutting was done with more, or lesse, skill the more or less fruitfull the tree would bee.

"A proposition was offered by Sr. Robert Moray about the planting of Timber in England and the preserving of what is now growing.

"Mr. Boyle shew'd a Puppey in a certaine liquour, wherein it had been preserved during all the hott months of the Summer, though in a broken and unsealed glasse.

"Sir James Shaen proposed a Candidate by Sr. Rob. Moray."

The experiments were afterwards carried out by "Curators of Experiments," and some account is here added of this office, which was first held by Robert Hooke.

The whole of this condensed history extends to only eighteen pages. It is illustrated by two plates containing portraits, not indeed of the first six Presidents, for the portrait of Sir Cyril Wyche is wanting, but of the Presidents from Lord Brouncker to the Earl of Carbery, with this exception. If these can be continued in future issues, and especially if some likeness of Wyche, and of any others which may be at present missing can be discovered and reproduced, it will make a valuable series. Portraits of Henry Oldenburg, the first Secretary, and of Robert Boyle, one of the earliest Fellows, are also given.

This introductory history of the Society's birth and youth is followed by other matters of more or less historical interest; the text of the Charters, a history of the Statutes, a list of the Benefactors of the Society from "Carolus Secundus, Fundator," downwards; a history of the Trusts, and so forth. We are also furnished with accounts of other institutions which are controlled by, or more or less closely connected with, the Royal Society, from the Kew Observatory, which is governed by a Committee appointed by the Royal Society's Council, to "The Physick Garden" of Chelsea, in which the Society has, as we read, "only a reversionary interest."

With respect to the latter institution, its connection with the Royal Society at its first foundation was closer than at present, and was rather curious. The garden, now more generally known as "The Botanic Garden, Chelsea," was founded by Sir Hans Sloane in I722, by a deed which enacted "That the garden should at all times hereafter be continued as a Physick Garden" by the Society of Apothecaries, which Society should yearly present to the Royal Society "fifty specimens or samples of distinct plants, well dried and preserved, and which grew in the said garden the same year, together with their respective names or reputed names, and so as the specimens or samples of such plants be different, or specifically distinct, and no one offered twice, until the complete number of two thousand plants have been delivered." This tale of two thousand was completed, we learn, in the year 1762 .

The "Record" contains, furthermore, statements of the origin and progress of various branches of work which the Society is still carrying on-the Government Grant for Scientific Investigations, which finds its spring and source in a letter addressed in the year 1849 by Lord John Russell to the late Earl of Rosse ; the Society's publications, comprising, besides monographs, the Philosophical Transactions-a noble series of volumes extending over more than two centuries-the Proceedings, and the Catalogue of Scientific Papers. The lastnamed arduous undertaking is, indeed, one of the most important branches of work at present being carried on by the Society. Some account of it, reprinted in part in the volume under review, appearcd in our pages some time since (NATURE, vol. xlv. p. 338). Then there is the library, the pedigree of which, so far as concerns some of the classical and antiquarian literature, is traced through the Arundel Library (presented to the Society in its earliest days by Henry Howard, afterwards sixth Duke of Norfolk) to Bilibald Pirckheimer, the friend of Albrecht Dürer, and from him to Matthias Corvinus, King of Hungary.

Sundry lists are added-a list of instruments and relics, a list of portraits, a list of medals, of presidents, treasurers and secretaries of the Society, and of persons to whom the Society's medals have been awarded, all of which, though arranged, as we have said, in official form, and obviously intended for official purposes, contain matter which the future historian of science cannot fail to find of great importance. Here, for instance, we learn that the Society has in its possession many relics of Sir Isaac Newton, including his telescope, the mask from the cast of his face taken after death, and the MS. of the Principia from which the first edition was printed. Here we learn that the Society treasures Boyle's airpump, Petty's double-bottomed boat, Huyghens's aerial telescope, Priestley's electrical machine, and the original Davy's safety lamp; and here, under the names of the successive Presidents, we find biographical notes which should be of value. Weld's "History of the Society" carries us down only to the year 1830 , and it is but an imperfect compilation at the best. When the story is continued by some later hand-as continued it certainly ought to be-the prospective series, of which this "Record" forms the first volume, should considerably lighten the historian's task.

$\mathrm{X}$.

\section{SOARING FLIGHT}

SOME time ago we referred, in an article on "Soaring $S$ Machines" (NATURE, vol. liii. p. 30 I ; see also p. $365)$, to the experiments which Mr. Percy S. Pilcher had commenced to carry out in this country on the lines laid down by the late Herr Lilienthal in Germany. Since that time Mr. Pilcher has gained considerable experience both in the making and handling of these aëro-planes, and quite recently he was able to make a successful ascent and descent before numerous spectators, under conditions which were not very favourable. An idea of the general shape of the machine he used may be gathered from the six accompanying illustrations, which are enlargements of six out of the numerous pictures taken during flight by means of the cinematograph. The machine itself weighed fifty pounds, the framework being made of bamboo; the latter could be easily folded up but when spread out and carried the sail material covered

No. 1450 vor. 56] 